\title{
Herbicide responses of mat-forming weeds of forest remnants in New Zealand
}

\author{
T.K. James and C.A. Dowsett \\ AgResearch, Ruakura Research Centre, Private Bag 3123, Hamilton 3240, New Zealand \\ Corresponding author: trevor.james@agresearch.co.nz
}

\begin{abstract}
Tradescantia fluminensis, Plectranthus ciliatus, Asparagus scandens, Hedera helix, Lamium galeobdolon and Selaginella kraussiana are all mat-forming invasive species that limit regeneration of native plants in forest remnants in New Zealand. Experiments using potted specimens of these weeds showed that low rates $(338-675 \mathrm{~g} / \mathrm{ha})$ of the herbicide triclopyr gave $>90 \%$ defoliation of T. fluminensis, A. scandens and L. galeobdolon, but a higher rate of $1350 \mathrm{~g} / \mathrm{ha}$ only gave $85 \%$ defoliation of $H$. helix. Diquat gave $85 \%$ defoliation of $P$. ciliatus. Aminopyralid was effective against S. kraussiana but was very slow acting. These experiments have identified herbicides and application rates for effective forest weed management to facilitate native plant regeneration in New Zealand temperate forests.
\end{abstract}

Keywords mat-forming weeds, triclopyr, diquat, aminopyralid, glyphosate, metsulfuron.

\section{INTRODUCTION}

In New Zealand there is an increasing need to protect native forest remnants from the effects of invasive weeds (Sullivan etal.2009a,2009b).Among the more challenging and serious introduced species are the mat-forming plants that prevent the regeneration of native plant species (Timmins \& Reid 2000; Standish et al. 2001). These weeds smother other woody seedlings and are difficult to control, requiring frequent applications of residual herbicides, such as metsulfuron and picloram, or the non-selective herbicide glyphosate (Reid et al. 2009; Weedbusters 2011). These herbicides frequently damage associated native canopy trees and understory plants (Kelly \& Skipworth 1984) and soil residues, especially of picloram, may prevent the establishment of the natives (Skurski et al. 2013).
An alternative approach could be to use less (or non-) persistent herbicides at application rates that temporarily suppress mat-forming weeds long enough to allow the establishment of native plant species (Crone et al. 2009). The initial stage of identifying such herbicides that could later be tested under field conditions was to compare a range of chemical candidates in glasshouse conditions for their speed and longevity of suppression of mat-forming weeds. To that end six locally common species were selected: wandering Jew (Tradescantia fluminensis Vell., Commelinaceae), plectranthus (Plectranthus ciliatus E.Mey., Lamiaceae), climbing asparagus (Asparagus scandens Thunb. Asparagaceae), ivy (Hedera helix L. Araliaceae), aluminium plant (Lamium galeobdolon (L.) L., Lamiaceae) 
and selaginella (Selaginella kraussiana (Kunze) A.Braun, Selaginellaceae).

After glyphosate, the two most widely used herbicides internationally for management of environmental weeds in general are triclopyr and clopyralid (Randall 1996). Although glyphosate is widely reported as having greater translocation under shade (e.g. Moosavi-Nia \& Dore 1979), it has also been found to give only partial defoliation of wandering Jew under forest canopies (Hurrell et al. 2008). Aminopyralid, closely related to clopyralid, has been shown to be very effective in killing some herbaceous weeds (James \& Rahman 2008; James \& Cooper 2012) and is now a component of the proprietary blend of herbicides sold under the trade name Tordon ${ }^{\mathrm{TM}}$ Brushkiller XT (with triclopyr and picloram) for control of brush weeds. Triclopyr and aminopyralid were selected for evaluation, both alone and in combination, for defoliation of the six test weeds. Although their average soil half-lives are 30 and 21 days for triclopyr and aminopyralid respectively (Anonymous 2014), it is generally accepted that at low rates and in the high organic carbon environment of forest soils that their persistence, and therefore effectiveness for weed control, will be shorter (James et al. 1999; Bolan et al. 2011). For plectranthus and selaginella, a further three treatments selected on the basis of local anecdotal evidence were evaluated in a second experiment. These were diquat, with and without carfentrazone, and glyphosate plus metsulfuron.

The two experiments with potted weeds compared the speed, duration and extent of defoliation by the herbicides when applied at quarter, half and full label-recommended application rates for general weed control using a knapsack sprayer.

\section{MATERIALS AND METHODS}

Both experiments were carried out on potted plants with propagation material collected from naturalised populations. Climbing asparagus was grown from young plants while the other five species were grown from rooted cuttings. Plectranthus, climbing asparagus and aluminium plant were collected from near Katikati and potted up during January 2011. Wandering
Jew and selaginella were collected from within Hamilton while ivy was collected from Ruakura Research Station. These were potted up during February/March 2011. All plants were gown in $15 \mathrm{~cm}$ diameter plastic pots filled with Daltons potting mix (bark fibre 15\%, bark fines 50\%, coco fibre $15 \%$, pumice $20 \%$ plus fertilisers and wetting agents) for approximately 4-6 months before treatment. A standard nutrient mix (Yates Thrive) was used to maintain optimal growth of the plants during this time. Plants were trimmed as required to produce dense clumpy plants about $300 \mathrm{~mm}$ in diameter at spraying to more closely replicate the structure of the plants in the field.

All herbicide treatments (Table 1) were applied on 21 July 2011 for Experiment 1 and on 9 September 2011 for Experiment 2, using a moving belt sprayer with a single TeeJet $8003 \mathrm{E}$ nozzle at $200 \mathrm{kPa}$, positioned $300 \mathrm{~mm}$ above the top of the plant to apply 750 litres/ha. In each experiment, the treatments were randomly assigned to four replicate plants and after treatment the plants were placed on glasshouse tables in a randomised block layout. The plants were visually assessed for damage eleven times over a 6-month period for Experiment 1 and five times over a 5-month period for Experiment 2. Initially, the damage score equated to plant brown-off compared to the untreated plants $(0-100$ scale, where $0=$ completely undamaged and $100=$ completely brown, i.e. no green leaves and no new growth). After brown-off reached maximum and regrowth began to appear, the amount of green material relative to untreated was estimated on a $0-100$ scale, where $0=$ no green material and $100=$ completely green. To create a damage score in keeping with the brown-off score the $\%$ green score was subtracted from 100 prior to recording.

For each species the damage scores were plotted against time and a model fitted using a generalized additive model with a penalized regression spline. This was performed in $R$ using the 'mgcv' package. The model allowed a different penalised regression spline to be fitted to each Treatment and Rate interaction. A line at 90\% damage was inserted in each graph and used as a standard reference point to assess the relative efficacy of the various treatments. 
Table 1 Rates and product names of herbicides used in Experiments 1 and 2.

\begin{tabular}{lll}
\hline Herbicide & Rates used $(\mathrm{g} / \mathrm{ha})$ & Formulation \\
\hline Experiment 1 (all treatments applied with Pulse & ${ }^{\circledR}$ Penetrant at $\left.0.1 \%\right)$ \\
triclopyr & $338,675,1350$ & Grazon $^{\mathrm{TM}}$ \\
aminopyralid & $17,34,68$ & Tordon $^{\mathrm{TM}} \mathrm{Max}$ \\
triclopyr + aminopyralid & $113+17,225+34,450+68$ & Tordon $^{\mathrm{TM}}$ PastureBoss $^{\mathrm{TM}}$ \\
\hline $\begin{array}{l}\text { Experiment } 2^{1} \\
\text { diquat }\end{array}$ & \\
diquat + carfentrazone & 400 & Reglone $^{\circledR}$ \\
glyphosate + metsulfuron & $3038+158$ & Reglone $^{\circledR}+$ Hammer $^{\circledR}$ \\
\hline
\end{tabular}

${ }^{1}$ Selaginella was only treated with diquat alone and the full rate of diquat + carfentrazone due to insufficient plants.

\section{RESULTS}

\section{Experiment 1}

For wandering Jew, the only treatment that reached $90 \%$ damage was triclopyr. The time to reach $90 \%$ damage was similar for the three different rates, between 5-16 days (Figure 1). This curve explains $97.5 \%$ of the variance within the data $\left(\mathrm{R}^{2}\right)$.

For plectranthus, no treatments achieved $90 \%$ damage with the high rate of triclopyr achieving $85 \%$ damage only after 150 days (Figure 1). This curve explains $91.5 \%$ of the variance within the data.

For climbing asparagus, the treatments that caused $90 \%$ damage were all rates of triclopyr and the high rate of the triclopyr + aminopyralid mixture. The estimated time to reach $90 \%$ damage for the medium and high rates of triclopyr was between 10-80 days (Figure 1). This curve explains $93.9 \%$ of the variance within the data.

For ivy, no treatments achieved $90 \%$ damage with the high rate of triclopyr achieving $85 \%$ damage only after 120 days (Figure 1 ). This curve explains $97.5 \%$ of the variance within the data.

For aluminium plant, all rates of triclopyr and both the medium and high rates of the triclopyr + aminopyralid mixture caused $90 \%$ damage, although the time required to reach this limit could only be calculated for the medium and high rates, viz. between 39-74 days and 22-45 days for the medium and high rates of triclopyr respectively and between 94-138 days and 4977 days for the medium and high rates of the triclopyr + aminopyralid mixture respectively
(Figure 1). This curve explains $92.2 \%$ of the variance within the data.

For selaginella, all of the treatments containing triclopyr caused $90 \%$ damage at about 150 days after treatment (Figure 1). This curve explains $97 \%$ of the variance within the data.

\section{Experiment 2}

For plectranthus, initially the two treatments containing the high rate of diquat achieved about $80 \%$ brown-off but these plants recovered very quickly. Conversely the glyphosate + metsulfuron treatment was very slow in acting, achieving $85 \%$ damage only after 120 days. Carfentrazone provided longer term control when added to diquat but only with the low rate $(450 \mathrm{~g} / \mathrm{ha})$ of diquat (Figure 2a).

For selaginella, the herbicide treatments were largely ineffective, with the diquat alone treatment only achieving $85 \%$ damage after 50 days and the plants rapidly recovering afterwards (Figure 2b).

\section{DISCUSSION}

Despite its activity on many broadleaf weeds, aminopyralid showed low activity on five of the six species with more than $60 \%$ damage seldom achieved and then only on climbing asparagus and aluminium plant. The single exception was selaginella where aminopyralid and its mixture with triclopyr performed better than triclopyr alone. In Experiment 2, the high rate (900 g/ha) of diquat (both alone and in combination with 


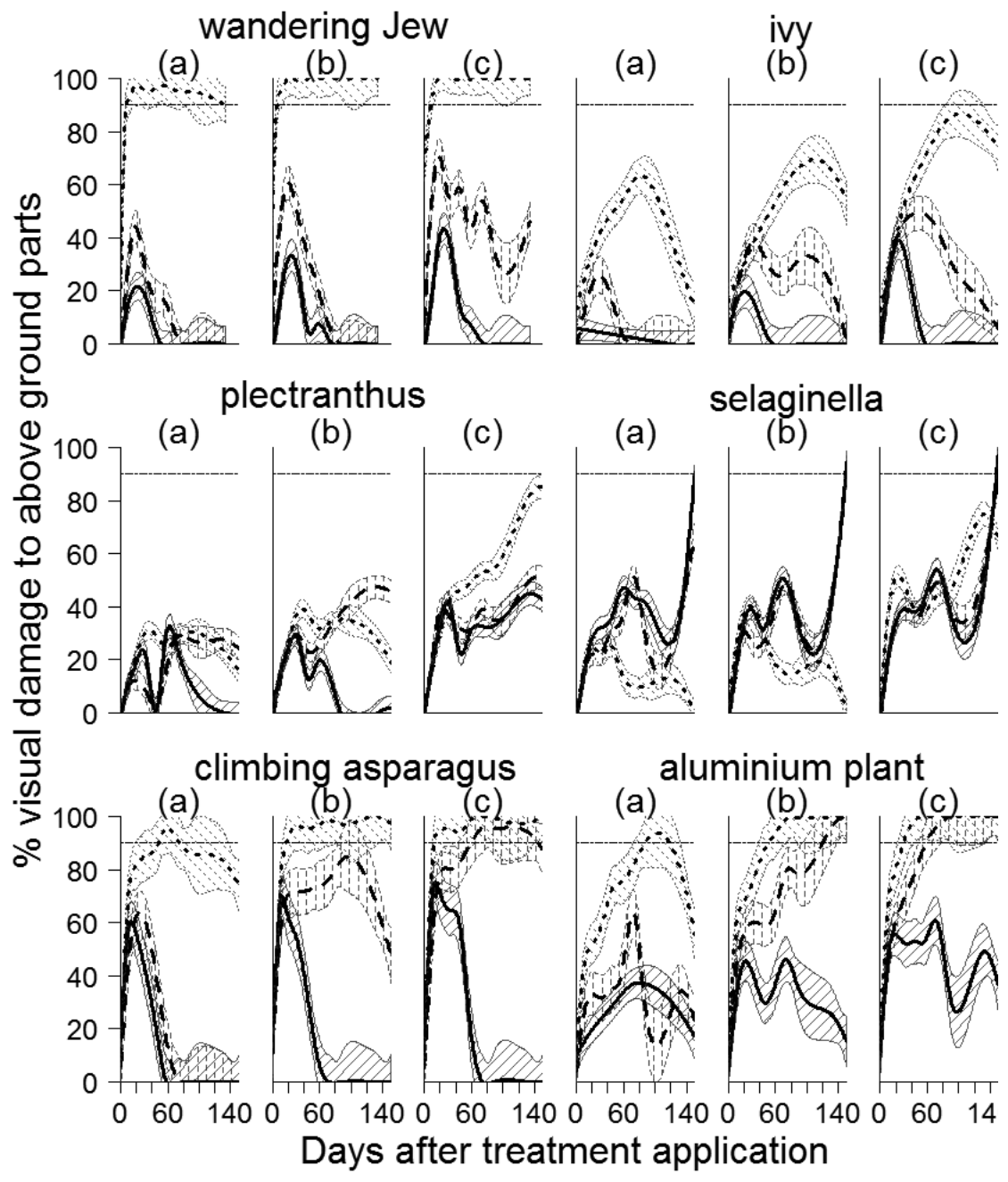

Figure 1 Visual damage (\%) to the above ground parts of six understory weeds for 6 months after three herbicide treatments (triclopyr: dotted line; triclopyr + aminopyralid: dashed line; aminopyralid: solid line) in Experiment 1. (a) herbicides applied at quarter rate, (b) herbicides applied at half rate and (c) herbicides applied at full rate. The lines are predicted fits from the generalized additive model and the shaded regions are the $95 \%$ confidence intervals about these predictions.

carfentrazone) provided faster defoliation of this weed than the treatments of Experiment 1, but the selaginella regrew quickly after peak damage was reached at 40-60 days. Diquat alone proved to be more effective than when mixed with carfentrazone.

Triclopyr performed well on four of the six species in these experiments. Most notable was its effect on wandering Jew where all three rates resulted in more than $90 \%$ damage for 130 days. However, by this time the plants treated with the low rate of triclopyr were showing some regrowth. This result is in keeping with previous results (Standish 2002; Hurrell et al. 2008). However, it has been observed in the field that wandering Jew height is a determinant of final efficacy with thicker stands requiring more herbicide (T.K. James, unpublished data). Climbing asparagus and aluminium plant responded similarly to all the treatments. Triclopyr resulted in greater than $90 \%$ damage at all rates but both 


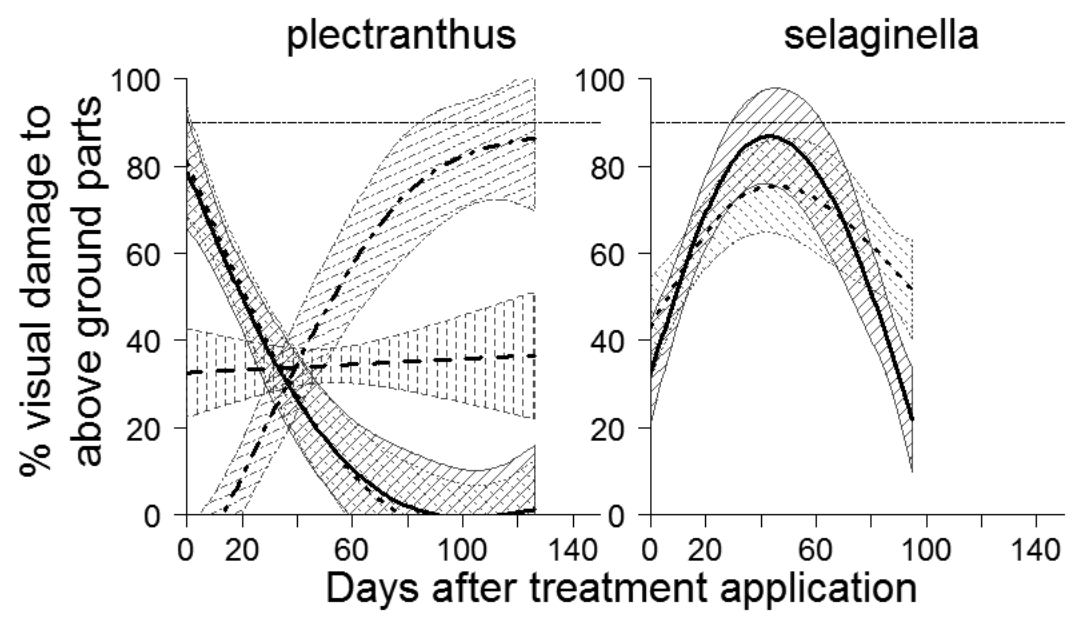

Figure 2 Visual damage (\%) to the above ground parts of (a) plectranthus and (b) selaginella for 5 months after four herbicide treatments (diquat: solid line; diquat+carfentrazone (full rate): dotted line; diquat+carfentrazone (half rate): long dashed line; glyphosate+metsulfuron: dot dashed line). The lines are predicted fits from the generalized additive model and the shaded regions are the $95 \%$ confidence intervals about these predictions.

species showed regrowth after 50-60 days in plants treated with the low rate (338 g/ha). The triclopyr + aminopyralid mixture also resulted in more than $90 \%$ damage in the medium and high rate treatments but overall the treatments were slower acting and showed regrowth sooner compared to triclopyr alone. This is most likely a reflection of the lower rate of triclopyr in the mixture treatments.

Plectranthus and ivy were more herbicide tolerant. The tough, shiny leaves of ivy were difficult to damage with the high rate of triclopyr taking 100 days to reach its maximum damage of about $85 \%$. Even this damage was not sustained in any of the treatments, with signs of regrowth appearing very quickly after peak activity was attained. Plectranthus has thick, hairy leaves (Popay et al. 2010) and although the use of Pulse Penetrant aided with the wetting and coverage of the leaves, the various treatments in Experiment 1 generally failed to cause much damage. In Experiment 2, diquat resulted in rapid brown-off ( $48 \mathrm{~h}$ ), but this was followed by signs of regrowth within 7 days. It appears that the high rate of diquat and its consequential more rapid brown-off interfered with the activity of carfentrazone, as here there was no long term damage from the carfentrazone and the plots of their damage are nearly superimposed (Figure $2 \mathrm{a}$ ). When a lower rate of diquat was used with carfentrazone, however, percent brown-off was lower (33\%) but this level of damage was sustained over a longer term due to the activity of carfentrazone.

In summary, these experiments have demonstrated that triclopyr is effective in defoliating wandering Jew, selaginella, climbing asparagus and aluminium plant at low (1/4 - 1/2 label) rates of application with less consequential persistence in the soil. For plectranthus, however, the use of diquat to obtain faster defoliation should be evaluated. None of the herbicides tested were sufficiently effective against ivy.

\section{ACKNOWLEDGEMENTS}

Thanks to Graeme Bourdôt for assistance with the preparation of this manuscript and to Maryann Pirie for statistical analysis and production of the figures. This experiment was funded by the Ministry of Business, Innovation and Employment under the Landcare Research project, Beating Weeds II. 


\section{REFERENCES}

Anonymous 2014. University of Hertfordshire, PPDB: Pesticide Properties DataBase. http:// sitem.herts.ac.uk/aeru/ppdb/en/index.htm (accessed 5/12/2014).

Bolan NS, Adriano DC, Kunhikrishnan A, James TK, McDowell R, Senesi N 2011. Dissolved organic matter: biogeochemistry, dynamics, and environmental significance in soils. Advances in Agronomy 110: 1-78.

Crone EE, Marler M, Pearson DE 2009. Nontarget effects of broadleaf herbicide on a native perennial forb: a demographic framework for assessing and minimizing impacts. Journal of Applied Ecology 46: 673-682.

Hurrell GA, James TK, Lusk CS, Trolove M 2008. Herbicide selection for wandering Jew (Tradescantia fluminensis) control. New Zealand Plant Protection 61:368-373.

James TK, Cooper JM 2012. Control of the recently-introduced weed butterprint (Abutilon theophrasti) in maize. New Zealand Plant Protection 65: 64-68.

James TK, Holland PT, Rahman A, Lu YR 1999. Degradation of the sulfonylurea herbicides chlorsulfuron and triasulfuron in a highorganic-matter volcanic soil. Weed Research 39: 137-148.

James TK, Rahman A 2008. Ragwort and nodding thistle control with novel 2, 4-D mixtures. New Zealand Plant Protection 61: 127-133.

Kelly D, Skipworth JP 1984. Tradescantia fluminensis in a Manawatu (New Zealand) forest: II. Management by herbicides. New Zealand Journal of Botany 22: 399-402.

Moosavi-Nia H, Dore J 1979. Factors affecting glyphosate activity in Imperata cylindrica (L.) Beauv. and Cyperus rotundus L. II: effect of shade. Weed Research 19: 321-327.
Popay I, Champion P, James T 2010. An illustrated guide to common weeds of New Zealand. New Zealand Plant Protection Society, Lincoln, New Zealand. 416 pp. ISBN 978-0-472-16285-6.

Randall J 1996. Weed control for the preservation of biological diversity. Weed Technology 10: 370-383.

Reid AM, Morin L, Downey PO, French K, Virtue JG 2009. Does invasive plant management aid the restoration of natural ecosystems? Biological Conservation 142: 2342-2349.

Skurski TC, Maxwell BD, Rew LJ 2013. Ecological tradeoffs in non-native plant management. Biological Conservation 159: 292-302.

Standish R J 2002. Experimenting with methods to control Tradescantia fluminensis, an invasive weed of native forest remnants in New Zealand. New Zealand Journal of Ecology 26: 161-170.

Standish RJ, Robertson AW, Williams PA 2001. The impact of the invasive weed Tradescantia fluminensis on native forest regeneration. Journal of Applied Ecology 38: 1253-1263.

Sullivan JJ, Meurk C, Whaley KJ, Simcock R 2009a. Restoring native ecosystems in urban Auckland: urban soils, isolation, and weeds as impediments to forest establishment. New Zealand Journal of Ecology 33: 60-71.

Sullivan JJ, Williams PA, Timmins SM, Smale MC 2009b. Distribution and spread of environmental weeds along New Zealand roadsides. New Zealand Journal of Ecology 33: 109-204.

Timmins SM, Reid V 2000. Climbing asparagus, Asparagus scandens Thunb.: a South African in your forest patch. Austral Ecology 25: 533-538.

Weedbusters 2011. The weed control handbook. Weedbusters New Zealand. New Holland Publishers (NZ) Ltd, Auckland. 112 pp. ISBN 978-1-86966-321-6. 